

\title{
Advanced Practice Registered Nurses: Gateway to Screening for Bipolar Disorder in Primary Care
}

\author{
Ann Marie Kriebel-Gasparro* \\ Temple University, College of Public Health, Department of Nursing, Philadelphia, PA 19140, USA
}

Received: March 20, 2015

Revised: June 02, 2015

Accepted: June 15, 2015

Abstract:
Objective:

The goal of this mixed methods descriptive study was to explore Advanced Practice Registered Nurses' (APRNs') knowledge of bipolar disorder (BPD) and their perceptions of facilitators and barriers to screening patients with known depression for BPD.

\section{Methods:}

A mixed method study design using surveys on BPD knowledge and screening practices as well as focus group data collection method for facilitators and barriers to screening.

Results:

89 APRNs completed the survey and 12 APRNs participated in the focus groups. APRNs in any practice setting had low knowledge scores of BPD. No significant differences in screening for BPD for primary and non primary care APRNs. Qualitative findings revealed screening relates to tool availability; time, unsure of when to screen, fear of sigma, symptoms knowledge of BPD, accessible referral system, personal experiences with BPD, and therapeutic relationships with patients.

\section{Conclusion:}

Misdiagnosis of BPD as unipolar depression is common in primary care settings, leading to a long lag time to optimal diagnosis and treatment. The wait time to diagnosis and treatment could be reduced if APRNs in primary care settings screen patients with a diagnosis of depression by using validated screening tools. These results can inform APRN practice and further research on the effectiveness of screening for reducing the morbidity and mortality of BPDs in primary care settings; underscores the need for integration of mental health care into primary care as well as the need for more APRN education on the diagnosis and management of bipolar disorders.

Keywords: Advanced practice registered nurses, Bipolar disorder, Bipolar disorder type I (BPD I), Bipolar disorder type II, Mixed methods, Primary care, Psychiatric mental health nurse practitioners, Screening.

\section{INTRODUCTION}

The World Health Organization ranks bipolar disorder (BPD) as one of the top ten causes of disability in the world [1]. The prevalence of mental illness in the US population is estimated to be $26 \%$ [2]. The current prevalence of bipolar disorders is estimated to be $4-5 \%$ of the U.S. population [3].

BPD is defined by the Diagnostic and Statistical Manual of Mental Disorders, fifth edition (DSM 5) as seven major subtypes called the "bipolar spectrum" [4]. Since this research was completed, the Diagnostic and Statistical Manual of

\footnotetext{
* Address correspondence to this author at the Temple University College of Public Health Department of Nursing, 3307 N. Broad Street, Philadelphia, PA 19140, USA; Tel: 215-707-5019; Fax: 215-707-1599; E-mail: amkg@temple.edu
} 
Mental Disorders (DSM) has been revised from the fourth edition to the fifth edition and has taken into account the last 15 years of published research. The DSM 5 includes bipolar I disorder (BPD I), bipolar II disorder (BPD II), cyclothymic disorder, substance/medication-induced bipolar and related disorder, bipolar and related disorder due to another medical condition, other specified bipolar and related disorder and unspecified bipolar and related disorder [4]. This research focused on Advanced Practice Registered Nurses (APRNs) knowledge of and screening behaviors in primary care for BPD I and BPD II.

\section{Definition of Bipolar Disorders}

BPD is a serious and chronic mental illness with varying degrees of mania, depression, or mixed episodes (both mania and depression) requiring timely diagnosis and treatment.

\section{Bipolar Disorder Type I}

(BPD I) is the most severe with at least one episode of mania alternating with major depression. Mania is a period of persistently elevated or irritable mood and increased goal-directed energy, lasting at least one week and present most of the day. During this mood disturbance, three or more of these symptoms are present: inflated self-esteem, decreased need for sleep, pressured speech, flight of ideas or a sensation of racing thoughts. The mood disturbance is severe enough to cause impairment in social or occupational functioning, often requires hospitalization, may include psychotic features and cannot be the effects of substance abuse or a medical condition [4]. Substances of abuse, prescribed medications and medical conditions can be associated with manic-like behaviors and are recognized in these diagnoses of a) substance/medication-induced bipolar and related disorder and b) bipolar and related disorder due to another medical condition [4].

\section{Bipolar Disorder Type II}

(BPD II) was thought to be a milder form of the disorder. BPD II is just as serious a condition as BPD I; it has longer periods of depression and mood instability with serious impairment in work and social functioning. The DSM 5 describes BPD II as a clinical course of recurring mood episodes consisting of one or more major depressive episodes lasting at least two weeks and at least one hypomanic episode lasting at least four days [4]. BPD II is difficult to diagnose unless specifically screened for, as patients are often not aware their symptoms are abnormal. Individuals often enjoy the increased energy and decreased need for sleep, so patients may not see these symptoms as being pathological. As a result, these patients may remain undiagnosed or misdiagnosed for many years [5].

\section{Global Burden of BPDs}

BPD continues to be a global health crisis; and was ranked as the fourth largest global burden of disease in people aged 10 - 25 years [6]. The global impact of BPDs is immense; the costs of BPDs worldwide include not only the management of the disease--but also the indirect costs to society such as the inability to work, absenteeism from work, suicide, morbidity and mortality from comorbidities such as obesity, cardiac disease, and drug and alcohol abuse, as well as the burdens on the family or caregivers [7]. Globally, life expectancy in such patients is decreased by 13.6 years for men and 12.1 years for women [8].

\section{Suicide Risk}

Suicide is a leading cause of death in patients with BPD. The estimates are $25 \%$ to $50 \%$ of patients with BPD will attempt suicide at least once in their lifetime and $8 \%$ to $19 \%$ will complete suicide [9]. A risk factor for suicide is misdiagnosis of BPD as unipolar depression. Placing patients on antidepressant monotherapy without a mood stabilizer can result in exacerbation of mania or mixed states with increased risks of suicidal ideations or attempts [10, 11]. It is now understood that BPD II may account for a large proportion of suicidal morbidity and mortality--emphasizing the importance of early and accurate diagnosis [12].

\section{Misdiagnosis is Common}

BPDs are under-recognized in clinical practice and often misdiagnosed as major depressive disorder [6]. Drancourt and colleagues [13] found in their study ( $n=501$ patients with BPD) the mean time to treatment was 9.6 years, and those patients with a hypomanic onset (BPD II), the mean time was even longer at 14.5 years. Diagnosis (especially for BPD II) and treatment is often delayed by the providers' lack of knowledge of the early presentations of BPD, lack of systematic screening practices and a failure to follow established guidelines [14]. 


\section{Screening Tools for BPD and APRN Role in Early Diagnosis}

The long lag time to correctly diagnose BPD could be reduced if a more effective screening approach is used to identify patients with BPD symptoms and interventions are initiated [15]. Baldassano [14] suggests that ideal screening tools include the Mood Disorder Questionnaire (MDQ), the Bipolar Spectrum Diagnostic Scale (BSDS) and the Hypomanic Personality Scale (HPS). These three tools have been validated, are brief and can be self-completed by patients. The MDQ consists of 13 questions, the HPS consists of 19 narrative questions, and the HPS is a self-report questionnaire of 48 items [15]. When symptoms of BPD are suspected, APRNs can screen patients using one of these tools. If screening is positive, the APRN can refer the patient to psychiatry, a Psychiatric Mental Health Nurse Practitioner (PMH-NP), Psychiatric Mental Health Clinical Nurse Specialist (PMH-CNS) or provide maintenance therapy in primary care in collaboration with these providers $[16,17]$.

The Institute of Medicine's (IOM) position statement "The Future of Nursing" recommended that APRNs be used to the utmost of their capabilities in providing care for people with a mental illness [17]. It would be appropriate for APRNs to screen patients for BPDs, begin treatment when needed and/or refer these patients to PMH-NPs, PMH-CNSs, and other behavioral health professionals for early diagnosis and treatment preventing delays to diagnosis and treatment. A wider screening approach in primary care, with the integration of mental health-utilizing the full scope of practice of APRNs and PMH-NPs-may ultimately decrease the high morbidity and mortality associated with undiagnosed BPDs [14].

\section{Research Questions}

There is currently no data on APRN knowledge of BPDs or research on their screening behaviors in primary care settings; the literature search found this data only on physicians. While there are a variety of screening tools for BPD available for use in primary care settings, there is a paucity of data on their use within APRN practice.

The primary purpose of this study was to determine APRN's knowledge of BPDs. The research question: What was the knowledge of advanced practice registered nurses in the primary care setting of bipolar disorders? comprised the quantitative portion of the study.

The secondary purpose of this study was to explore APRN perceived barriers and facilitators to screening. The research question "What were APRNs' perceptions of the barriers and facilitators to screening for bipolar disorder in their daily practice?" comprised the qualitative portion of the study.

\section{METHODOLOGY}

A mixed methods study design with sequential data collection was used to gain a broader perspective than would be obtained from using one method alone [18]. This method is useful when different questions need different answers and a quantitative design may need to embed qualitative elements [19]. Both types of data were collected and the researcher gained more in depth perspectives than by using one method alone [20]. Quantitative survey data was collected first and qualitative focus group interviews were conducted last [18]. Data were analyzed independently and mixing occurred last during the data interpretation stage.

\section{Data Collection}

To obtain a large sample of APRNs, the study was conducted at the Pennsylvania Coalition of Nurse Practitioner's (PCNP) Annual Conference in Pittsburgh, Pennsylvania in November, 2011 with an attendance of almost 500 APRNs. The researcher gave an educational session titled 'Emotional Extremes', which had an attendance of 108 APRNs; a pretest and posttest knowledge survey on BPDs was offered to this group. Eighty-nine APRNs completed the survey and two six member focus groups were conducted on the following day.

The pretest/posttest consisted of a 12-item researcher developed survey previously validated by a pilot study and expert content reviewers and contained five general question on BPDs; two on BPI and five on BP II to evaluate APRN knowledge of BPDs. The survey was developed from the current literature on the signs and symptoms of BPDs and had good internal consistency (Cronbach's alpha $(\alpha=0.73)$. Questions 1, 2, 3, and 9 were specific to BP II disorder with a Cronbach's alpha $(\alpha=0.77)$.

The qualitative sample consisted of twelve non-redundant APRNs attending the PCNP Annual Conference who were invited to the focus groups during the conference. The focus groups consisted of two groups of six participants each and explored their perceptions of barriers and facilitators to screening for and treatment of BPD and were 
conducted without any predetermined theoretical framework. Focus-group interviews used a voice recorder and previously piloted semi-structured survey questions. Data was analyzed using Atlas-ti 7.0.81 (1993-2012) computer assisted qualitative data software program (QDAS) coding process to develop themes and categories [19].

\section{Protection of Human Subjects}

This mixed method study was approved by Drexel University Institutional Review Board as an exempt study and consent forms were not required. Confidentially and anonymity were maintained and no protected health information was recorded. Data obtained for the study were recorded by code numbers for data analysis.

\section{Data Analysis}

Data analysis provided information on the knowledge level and behaviors of APRNs in their practices. To better characterize variables impacting APRN knowledge, demographics were used to estimate their relationship with knowledge scores. Analysis of variance was performed for APRN knowledge, practice in primary care and age. Descriptive statistics using IBM SPSS version 20 (1999 - 2011) used list-wise deletion to exclude missing values. Missing data was present in three of the 89 subjects and was limited to data point in these three subjects. The small number of missing did not support a meaningful evaluation of missingness and it was assumed to be missing completely at random (see Table 1).

Focus group data were analyzed using the constant comparative analysis method as described by Creswell [20]. Themes that emerged were developed through coding, memos, data reduction and synthesis using Atlas. Ti QDAS. The choices of validity procedures for the qualitative study were based on the criteria of Lincoln and Guba [21] for establishing trustworthiness in qualitative research. These criteria include credibility, transferability, dependability, and confirmability [21].

Trustworthiness was established through the techniques of prolonged engagement in the field of study, persistent observation, peer debriefing, and member checking of the data analysis and themes. Member checking consists of taking the data interpretations back to the participants for confirmation of the accuracy and credibility of the information collected during the interviews. Because the participants of the focus groups were from a large geographic area of Pennsylvania, copies of the themes were mailed to the twelve participants. Of the two tables of themes (one for barriers and facilitators to screening, the other for treatment), that were mailed, eight were returned and accepted without changes.

A peer debriefing session was held by telephone call with a doctorally prepared qualitative researcher familiar with Atlas. Ti, and several areas of potential bias were identified and corrected. Two qualitative research experts served as peer auditors and reviewed the study documents (focus group transcripts and data analysis documents) to determine consistency and coherent logic throughout the inquiry. The peer auditors provided objective, expert feedback to the researcher, leading to better articulated findings. An external auditor thoroughly examined the audit trail consisting of the original focus group transcripts and data analysis documents. Automatic logs of coding changes were maintained by Atlas-ti and supported by an archive of project file backup. Atlas-ti allowed an audit trail to be maintained, tracking the development of analysis with annotations for major decisions and researcher input.

\section{RESULTS}

\section{Demographics}

\section{Survey Group}

The mean age of the eighty-nine APRNs for the survey was 49.9 years with an average of 10.9 years in practice. The demographics of this study sample were similar to the national demographics of APRNs in the U.S. for age and average years in practice at 49.5 and 12.2, respectively (American Association of Nurse Practitioners, 2014). Five percent of this sample was PMH-NPs, comparable to the national distribution of $3.2 \%$ (American Association of Nurse Practitioners, 2014). Demographics for seeing patients with depression, using the MDQ and screening behaviors are listed in Table 1. The major differences in the forty-six APRNs practicing in primary care were that none were psychiatric NPs, 97.8\% saw patients with depression and less than half screened for BPD. The forty APRNs not in primary care reported that $72.5 \%$ saw patients diagnosed with depression. Over $62 \%$ did not screen for BPDs; and $27.5 \%$ did screen for BPD. 


\section{Focus Group}

The mean age of the twelve focus group APRNs was 53.3 years with a mean of 13.5 years experience. This sample was slightly older with more years experience than the quantitative sample. The focus group also differed slightly from the national averages of 49.5 years for age, and 12.2 years in practice (American Association of Nurse Practitioners, 2014). All twelve APRNs reported their specialty as Family/Adult NP.

\section{Survey Results}

\section{Knowledge of Bipolar Disorders}

The differences in overall knowledge between APRNs in primary care and those not in primary care were evaluated using the mean scores and an independent sample $t$-test. Comparison of total survey scores for APRNs in primary care $(\mathrm{M}=7.96, \mathrm{SD}=2.46 ; \mathrm{n}=46)$ and APRNs not in primary care $(\mathrm{M}=7.50, \mathrm{SD}=2.75 ; \mathrm{n}=40)$ were not statistically significant $(t(.81)=84, p=0.51)$.

Analysis of variance was performed for APRN knowledge, practice in primary care, and age; between-subject factors revealed a main effect of screening for BPD on knowledge scores $(F(1,71)=13.34, p=<.001, p 5=0.158)$. The predicted interaction among age and practicing in primary care on knowledge scores was not significant $(F(1,71)=$ $0.000, p=0.996)$.

Table 1. Demographic and clinical characteristics of survey group $(\mathrm{N}=89)$.

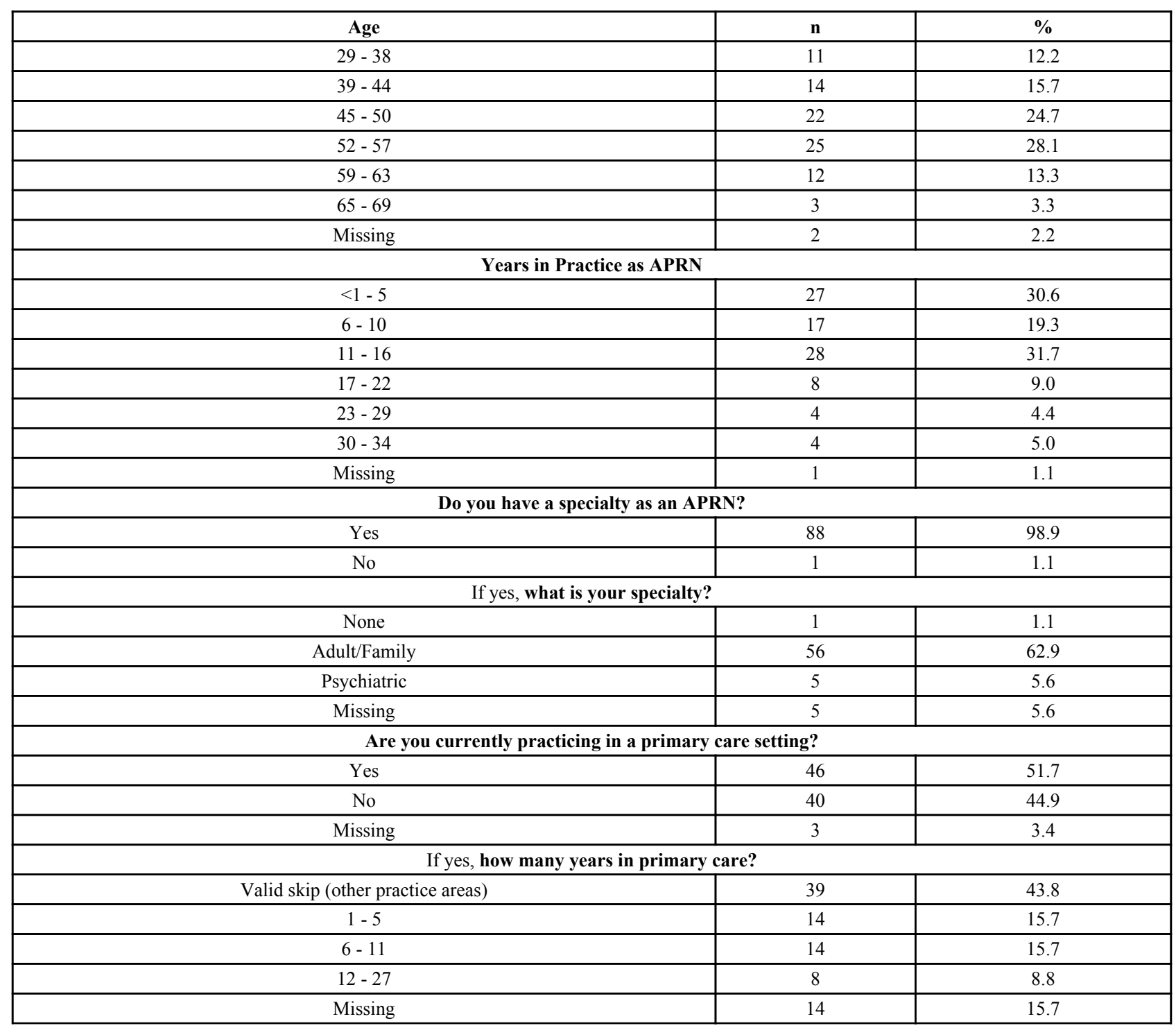


(Table 1) contd.....

\begin{tabular}{|c|c|c|}
\hline Age & $\mathbf{n}$ & $\%$ \\
\hline \multicolumn{3}{|c|}{ If not primary care, what practice setting? } \\
\hline Valid skipped questions (in primary care) & 47 & 52.8 \\
\hline Pediatrics & 3 & 3.4 \\
\hline Psychiatry & 8 & 9.0 \\
\hline Acute care & 7 & 7.9 \\
\hline Education & 5 & 5.6 \\
\hline Surgery & 4 & 4.5 \\
\hline Occupational health & 5 & 5.6 \\
\hline Women's health & 2 & 2.2 \\
\hline GI & 2 & 2.2 \\
\hline Internal Medicine & 2 & 2.2 \\
\hline Other & 3 & 3.4 \\
\hline Missing & 1 & 1.2 \\
\hline \multicolumn{3}{|c|}{ Are you a psychiatric NP? } \\
\hline Yes & 5 & 5.6 \\
\hline No & 84 & 94.4 \\
\hline \multicolumn{3}{|c|}{ If yes, how many years in psychiatric practice? } \\
\hline Valid skip (not in psychiatric practice setting) & 83 & 93.3 \\
\hline 4 years & 1 & 1.1 \\
\hline 5 years & 2 & 2.2 \\
\hline 7 years & 1 & 1.1 \\
\hline 13 years & 1 & 1.1 \\
\hline Missing & 1 & 1.1 \\
\hline \multicolumn{3}{|c|}{ Do you see patients with depression in your practice? } \\
\hline Yes & 74 & 83.1 \\
\hline No & 11 & 12.4 \\
\hline Missing & 4 & 4.5 \\
\hline \multicolumn{3}{|c|}{ If yes, do you screen for bipolar disorder? } \\
\hline Valid skip & 4 & 4.5 \\
\hline Yes & 32 & 36.0 \\
\hline No & 49 & 55.1 \\
\hline Missing & 4 & 4.5 \\
\hline \multicolumn{3}{|c|}{ Do you use the MDQ to screen? } \\
\hline Valid skip & 4 & 4.5 \\
\hline No & 53 & 59.6 \\
\hline Yes & 25 & 28.1 \\
\hline Missing & 7 & 7.9 \\
\hline \multicolumn{3}{|c|}{ What method of screening do you use for BPD? } \\
\hline Valid skip (do not see depressed patients) & 4 & 4.5 \\
\hline Do not screen for BPD & 48 & 53.9 \\
\hline MDQ & 22 & 24.7 \\
\hline Interview (unstructured) & 7 & 7.9 \\
\hline PHQ-9 & 2 & 2.2 \\
\hline CES-10 & 1 & 1.1 \\
\hline Missing & 5 & 5.6 \\
\hline \multicolumn{3}{|c|}{ Approximately how many patients do you see monthly with depression? } \\
\hline None & 4 & 4.5 \\
\hline $3-9$ & 13 & 14.6 \\
\hline $10-20$ & 33 & 37.0 \\
\hline $25-35$ & 9 & 10.0 \\
\hline $40-60$ & 8 & 8.9 \\
\hline $75-90$ & 2 & 2.2 \\
\hline $150-360$ & 4 & 4.4 \\
\hline Missing & 10 & 11.2 \\
\hline
\end{tabular}


There was a significant relationship between APRN years of practice in primary care on knowledge $\operatorname{scores}(F(7,21)$ $=3.27, p=0.016)$, the more years practiced in primary care, the higher the BPD knowledge scores. There was no significant relationship between knowledge scores and APRN use of the Mood Disorder Questionnaire $(F(7,21)$ $=0.930, p=0.504)$ or on the number of depressed patients seen by the APRN monthly on knowledge scores $(F(7,21)$ $=2.09, p=0.09$ ).

The major finding from the quantitative survey of APRN knowledge of BPDs was that there was no statistically significant difference between APRNs who practiced in primary care versus those who did not practice in primary care (Table 2); this was contradictory to the investigators original assumption that APRNs practicing in primary care would have more knowledge of BPDs. The knowledge survey results indicated that APRNs in both primary care and nonprimary care practices have similar insufficient knowledge of BPDs; especially of BPD II. The low scores on questions $1,2,3,4,9$, and 11 (particular to knowledge of BPD II) indicated that all APRNs, regardless of practice area in this study, had less than $50 \%$ knowledge of BPD II (See Table 3). The next most significant finding was that $83.1 \%$ ( $=74$ ) of all of the APRNs stated they saw patients with a diagnosis of depression in their practices, but $55.1 \%(n=49)$ admitted they did not screen these patients for BPDs.

Chi-square tests of independence were performed to examine the following relationships with no statistical significance:

- The effect of screening behaviors of APRNs in primary care on knowledge scores

- Knowledge survey scores between APRNs that practiced in primary care and those who did not practice in primary care

The effect of screening behaviors for APRNs not in primary care on knowledge scores showed no significant differences for questions 3-8 and 10-12 (Table 3). There was a significant difference at the $\mathrm{p}<0.001$ level for questions 1, 2, and 9; which related to knowledge of BPD II disorders (Table 2).

\section{Focus Group Themes}

Focus group themes were developed without a preconceived theoretical foundation. Themes were sorted by prevalence of quotations on the topics of screening and treatment of depression and BPDs (see Table 4).

\section{Facilitators for Screening}

Focus group data analysis revealed the top five themes in descending prevalence for facilitators to screening: 1) Availability of the screening tool, 2) Therapeutic relationships with patients, 3) Knowing the symptoms of BPD and when to screen, 4) Accessible psychiatric referral systems in place and 5) APRN personal experiences with BPD.

Availability of screening tools, including electronic medical record (EMR) reminders, were cited as powerful facilitators to screening patients, even during a busy day. One APRN practicing in a primary care clinic remarked:

Table 2. Percent correct for knowledge of BPDs survey of APRNs per question $(\mathbf{N}=89)$.

\begin{tabular}{|c|c|c|c|}
\hline & $\%$ Correct & $\underset{\mathbf{n}=}{\boldsymbol{f}}$ & Missing \\
\hline Q1: BPD I has more severe mania (true). & 42.7 & 38 & 0 \\
\hline Q2: BPD II has more depression than BP1 (true). & 36.0 & 32 & 0 \\
\hline Q3: Higher Risk of Suicide in BPD II than BPD I (true). & 38.2 & 34 & 1 \\
\hline Q4: BPD II often misdiagnosed as depression (true). & 76.4 & 68 & 0 \\
\hline Q5: The MDQ is a screening tool for bipolar disorder (true). & 73.0 & 65 & 1 \\
\hline Q6: BPD I includes psychosis, homicidal or suicidal ideations (true). & 52.8 & 47 & 1 \\
\hline Q7: Mania is a state of being excessively happy (false). & 60.7 & 54 & 0 \\
\hline Q8: Bipolar symptoms are often missed in primary care (true) & 95.5 & 85 & 0 \\
\hline Q9: BPD II often requires hospitalization for severe mania (false). & 43.8 & 39 & 0 \\
\hline Q10: BPDs can be cured with medication and treatment (false). & 76.4 & 68 & 0 \\
\hline Q11: Individuals with BPD often wait 10 years or longer for a correct diagnosis (true). & 93.3 & 83 & 0 \\
\hline Q12: One of the benefits of screening for BPDs is decreasing the risk of suicide (true). & 87.6 & 78 & 0 \\
\hline
\end{tabular}


Table 3. Number of APRNs that Screen or do not Screen in primary care vs not in primary care $($ Missing $=8)$.

\begin{tabular}{|c|c|c|c|c|c|}
\hline & Does Not Screen & Screens for BPD & & $\boldsymbol{X} 2$ & Sig \\
\hline Not in primary care & $\begin{array}{c}51.0 \% \\
\mathrm{n}=25\end{array}$ & $\begin{array}{c}34.4 \% \\
\mathrm{n}=11\end{array}$ & $\mathrm{~N}=36$ & 0.172 & 0.141 \\
& $\begin{array}{c}69.0 \% \\
\mathrm{n}=24\end{array}$ & $\mathrm{n}=21$ & $\mathrm{~N}=45$ & \\
& In Primary Care & & & \\
\hline
\end{tabular}

"We have the PHQ-9 scale for depression-I use that a lot, mainly because it's in our computerized system (EMR) . . . but we also have hard copies (the MDQ) so people can read it . . . if they give any indication that they might be BP, I have them (fill out the MDQ). . we have it right in the room, I ask them, please fill this questionnaire out."

The second major theme was therapeutic relationships. One APRN stated how important it was to develop a relationship with her patients before asking about mood disorders:

"Yeah, I've learned over the years, and especially, I target those people that are BP, and you don't want to broach that subject the first time you see them. . you want to develop a relationship with them. . and then you just say, how's your mood been?"

\section{Barriers to Screening}

Barriers were described as tools not being available, the APRN did not always think of it or felt uncomfortable with screening. Some preferred to have psychiatry do the screening, especially for BPD. Although the majority stated they could screen for depression, many admitted they did not perform screening with all patients. Themes for barriers to screening are listed in descending prevalence: 1) APRN forgetting or not sure when to screen, 2) Patient reluctance to complain of symptoms (fear of stigma) and 3) Shortage of time in a typical visit and shortage of primary care providersnecessitating rushed visits without time for more screenings. One APRN noted that many of her patients do not want to 'hear that they may have BPD because of the stigma of having a mental disorder'. As one APRN stated:

“I just ask 'how's your mood been?'. . . and you may get all kinds of different answers. Because it's amazing how many people won't tell you how they're feeling, they won't want to bring it up . . . some of them will say, 'oh, I'm okI'm doin' ok'; and some of them sigh right away . . . and say 'sometimes I feel blue' and I say, what do you mean by that?"

Another APRN reflected on time limits experienced in daily practice:

“There's something else, you know, the 15-20 min appointment is not enough (for more screening)."

\section{Facilitators for Treatment}

The four most cited facilitators for treatment of BPD in descending prevalence were:1) Integrated mental health or referral systems in place, 2) APRN knowledge/education of BPDs, 3) APRN comfort treating BPDs and 4) Patients having insurance or funding to obtain treatment. Having integrated mental health or referral systems in place was the most common theme as a facilitator for treatment of BPDs. Many APRNs stated having mental health providers integrated into their practice was an important facilitator to screening and treating BPD.

\section{One APRN remarked:}

"We have integrated (services)-it's a health and wellness center, so we have counseling and psych with health services-(patients) get counseling, see the psychiatrist ... and the medical people do medication management, it's all integrated. Our director is a psych CNS-who has done a lot of presentations about our model-how good it is having all the services under one umbrella; coordination of care, multidisciplinary meetings every week on anybody in those services."

\section{Barriers to Treatment}

The six themes in descending prevalence relating to barriers to treatment were: 1) Patients have no insurance, 2) APRN lack of knowledge or need for education, 3) (Patient) side effects of treatment, 4) Patient lack of insight regarding mental illness, 5) Long wait for treatment and 6) Misdiagnosis of BPD as depression. A major theme was APRN lack of knowledge of BPDs and the need for education. Several APRNs voiced concern over not having enough knowledge about BPD to start medications; and one NP commented: "They (BP patients) are well beyond my area of expertise. . ." One NP responded to the researcher's question, 'Do you feel that NPs know enough about BPD?' as 
follows:

"I don't think so-and the thing that really bugs me is when the drug companies give . . those half day seminars ... you're not going to tell me in a half a day what I'm going to have to learn to take care of these patients, I feel like I really need a lot more to take care of them."

Another APRN shared the following:

"(Because of) horrible mental health services-we (NPs) have to learn, we put patients on meds and stabilize them, have the PCPs follow them, when they finally get to psychiatry-they are stable or just get fine-tuned with meds everyone is happy with this system."

\section{DISCUSSION}

Results of the quantitative survey showed this sample of APRNs had insufficient knowledge of BPDs and was confirmed by statements made by APRNs in the focus groups. These results were similar to the literature that found providers in primary care had little knowledge of BPDs or training in management of mental disorders. In addition, the survey results found the majority of APRNs saw patients with depression, whether practicing in primary care or other areas, yet most were not screening these patients for BPD. This finding coincides with the literature that most primary care providers do not screen patients with depression for BPDs [22].

Analysis of the themes of both facilitators and barriers identified several themes that were diametrical opposites; for example, a common theme of a barrier to screening was lack of knowledge of BPDs; and a commonly mentioned facilitator to screening was the NP knowing the symptoms of BPD and knowing when screening would be appropriate. Another example was APRN identification of a lack of patient insurance as a barrier to treatment; in contrast to the patient having insurance as a facilitator to treatment for BPDs.

\section{Limitations of Study}

Participants were limited to APRNs who were members of the PCNP attending the Annual Conference in the year 2011. APRNs with missing data sets were included in the study; intent to treat protocol was used to include the participants who did not complete all of the data $(n=3)$. The reasons APRNs in non-primary care practices were screening depressed patients for BPDs was not explored in the focus groups and suggests an area for further research.

The results of this study supports the integration of mental health services into primary care; more specifically, optimizing the skills of PMH-NP or PMH-CNSs to providing mental health services in primary care settings in collaboration with APRNs and other PCPs.

Before this integration can take place, APRNs, by their own admission, need more education on the presentation and management of BPDs in the primary care setting.

Table 4. Themes of facilitators and barriers for screening and treatment.

\begin{tabular}{|c|c|c|c|}
\hline \multicolumn{2}{|c|}{ Facilitators } & \multicolumn{2}{|c|}{ Barriers } \\
\hline Screening & Treatment & Screening & Treatment \\
\hline $\begin{array}{l}\text { 1. Availability of screening } \\
\text { tool } \\
\text { 2. Therapeutic relationships } \\
\text { with patients } \\
\text { 3. Knowing the symptoms of } \\
\text { BPD and when to screen } \\
\text { 4. Accessible psychiatric } \\
\text { referral systems in place } \\
\text { 5. Accessible psychiatric } \\
\text { referral systems in place }\end{array}$ & $\begin{array}{l}\text { 1. Integrated mental health } \\
\text { or referral systems in place } \\
\text { 2. APRN knowledge \& } \\
\text { education of BPDs } \\
\text { 3. APRN comfort treating } \\
\text { BPDs } \\
\text { 4. Patients having insurance } \\
\text { or funding to obtain } \\
\text { treatment }\end{array}$ & $\begin{array}{l}\text { 1. APRN forgetting or not sure } \\
\text { when to screen } \\
\text { 2. Patient reluctance to } \\
\text { complain of symptoms (fear of } \\
\text { stigma) } \\
\text { 3. Shortage of time in a typical } \\
\text { visit and shortage of primary } \\
\text { care providers }\end{array}$ & $\begin{array}{l}\text { 1. Patients have no } \\
\text { insurance } \\
\text { 2. APRN lack of knowledge } \\
\text { or need for education } \\
\text { 3. (Patient) side effects of } \\
\text { treatment } \\
\text { 4. Patient lack of insight } \\
\text { regarding mental illness } \\
\text { 5. Long wait for treatment } \\
\text { 6. Misdiagnosis of BPD as } \\
\text { depression }\end{array}$ \\
\hline
\end{tabular}

In accordance with The Robert Wood Johnson Foundation (RWJF) and the Institute of Medicine (IOM) initiative, 'The Future of Nursing: Leading Change, Advancing Health', nurses should practice to the full extent of their education and training. Screening for and management of mental health conditions in primary care is in alignment with this initiative [23]. APRNs in partnership with PMH-NPs can have a direct impact on reducing the morbidity and mortality 
of undiagnosed BPDs by implementing screening practices for all patients with a known diagnosis of depression in primary care practice through innovative strategies.

\section{IMPLICATIONS FOR NURSING}

\section{Innovations in Mental Health Care Critically Needed}

Integration of mental health into primary care is one innovation that is critical given the high prevalence of mental illness, the interconnectedness of mental and medical illness, the difficulty in getting patients to follow up in separate places and the limited availability of specialized mental health services.

\section{Patient Centered Medical Homes}

The medical home concept is the centerpiece of health care reform and should be accessible, comprehensive, person-centered, and compassionate. These goals cannot be achieved if there is no mental health in the medical home. "There is no health without mental health," said Dr David Satcher in his first Surgeon General's report on mental health [24]. APRNs specialized in primary care and mental health need to be proactive in leading Patient-Centered Medical Home (PCMH) initiatives to remain at the forefront of providing cost-effective and comprehensive screening, wellness care and disease management and to ensure mental health is integrated into the PCMH.

As the need for mental health screening and services increases, APRNs, PMH-NPs and PMH-CNSs need to be on the forefront of developing and leading Psychiatric Patient-Centered Medical Homes (PPCMH) [25]. The concept of PPCMH needs to be embraced and embedded within primary care practices, where mental health experts (psychiatrist or PMH-NP), social workers trained in mental health and counselors are on site or available to evaluate patients and provide diagnosis and treatment [25 - 28].

\section{Innovations Using Technology}

Telehealth has the potential to improve clinical care of people with BPDs in many settings-rural, urban, and undeveloped countries, and improve the global shortage of health professionals through collaboration and training [29]. Many individuals with BPD actively seek information and support online, and find the internet more helpful than information from printed sources or healthcare providers [30, 31]. Hogan and colleagues found the internet the most popular source of information for people with mental health problems [32, 33]. Research suggests online is preferred over face-to-face interaction because of the ease of accessing advice, reduced stigma, avoiding a mental health record and more willingness to self-disclose online [34].

Innovations using Telehealth modalities are needed to create collaborative programs that connect BP individuals to primary care providers and psychiatric care and can include real-time screening of patients with depression at home or in office waiting areas. These initiatives can reduce the lag times to screening and diagnosis. APRNs and PMH-NPs and CNSs are ideally situated to lead this innovation.

Another innovation is e-therapy-a licensed mental health care professional providing mental health services via email, video conferencing, virtual reality technology, chat technology or any combination of these. The use of e-therapy has been rapidly expanding with growing evidence that provision of mental health services over the internet is clinically efficacious and cost effective. Current literature on the therapeutic relationships in e-therapy is scant [35] and should be further researched by APRNs and PMH-NPs.

APRNs can lead the development of smart collaborations using innovative use of electronic health records (EHRs) and iPad applications to incorporate screening tools for recognition of BPDs, educational apps for patients and family members on symptoms, management and life-long care of BPD [28].

\section{Innovations in APRN Education}

APRN education needs to focus on collaborative or shared care models, in which joint consultations between primary care providers and mental health specialists occur in clinical programs and practice to provide ongoing training and education. Interprofessional education for BPD should consider the use of simulation technology in nursing curricula to provide opportunities for nursing, medical, social work and therapy students in the recognition, screening and care of BPD patients.

APRNs in this study identified they need more education on BPDs. Didactic curricula and clinical practicums for 
APRN education need to incorporate screening, management and appropriate referral strategies for BPD, as well as other chronic mental health disorders. There is also a need for training programs for APRNs who are already practicing and should include graduate level courses in the management of psychiatric disorders most commonly encountered in primary care. The implementation of these strategies can reduce the long lag time in diagnosis and treatment for these individuals.

\section{CONCLUSION}

The psychiatric literature for more than two decades has reiterated that patients with depression need to be screened for BPD in primary care settings [36 - 38]. BPD continues to be overlooked and not treated; or misdiagnosed and inappropriately treated as depression. Failure to identify symptoms of BPD can lead to the prescription of antidepressants, the induction of rapid cycling, mania, mixed states and treatment resistance [39]. More recently, studies have focused on primary care practices needing to screen for BPD [40 - 42], but the barriers remain that primary care providers often lack the time and training to screen for BPDs [39], barriers that were voiced by the APRNs in this study.

\section{Closing the Gap}

The results of this study show that APRN screening behaviors are inconsistent at best; and in most cases, not done at all. There continues to be a significant gap between psychiatry, the psychiatric literature and primary care. There are some signs the gap is closing as more research is focused on screening and managing BPDs in primary care settings [43] by both psychiatric and primary care practices; and this situation is promising [27].

\section{APRNs as Gatekeepers for BPD Screening}

Unfortunately, interest in screening for BPDs is not as evident in the nursing community. As of the date of this writing, few publications were found authored by either nurses or APRNs on the subject of screening for BPDs. The results of this study indicated nurses are most often not aware of BPDs, or in many cases, if they are aware, they often knowingly turn a 'blind eye' to these patients if they feel they do not know enough to treat or have no resources to refer or manage them. The focus group APRNs stated they did not have the education or knowledge to manage patients with BPDs, which the knowledge survey scores corroborated.

A surprising majority of APRNs had less than 50\% knowledge of BPD II disorders; a concern of magnitude in light of the public health costs of the morbidity and mortality of BPDs. There is a plethora of research indicating BPDs are underdiagnosed or misdiagnosed and not treated for years, and that primary care providers-including APRNs-need to be the gatekeepers of screening for this disorder if it is to be diagnosed and treated in a timely and cost effective manner. The gap between the BPD patient and psychiatric care must be filled by primary care providers. APRNs and PMH-NPs can and should be one of the primary care providers to fill this gap.

\section{Public Health Impact}

BPD continues to be a significant public health crisis in the U.S. [1, 44, 45]. Untreated BPD will continue to be a source of completed suicides; and unless more patients with a known diagnosis of depression are specifically screened, these suicides will continue and most likely increase [46 - 48]. There is a critical need for more PMH-NPs (3.2\%) (American Association of Nurse Practitioners, 2014) to care for the increasing numbers of individuals in the U.S. and globally with mental health needs.

Screening is a necessary first step that needs to be implemented in primary care for the purpose of preventing suicides, but also to improve the quality of life for individuals who are often not aware that they have BPD [49 - 52]. It is usually only though concerted screening efforts that individuals with the 'softer' type of BPD, such as BPD II, are identified [53].

This is the first study that has looked at the knowledge and screening behaviors of APRNs in primary care of BPDs, as well as their perceptions of facilitators and barriers to screening or treating BPD. The focus groups identified multiple barriers that will require innovative policy and system changes to rectify (i.e. the uninsured). Other barriers would require little effort to remove; such as adding the screening questions to the EMR, or having the paper survey in the room.

\section{Future Research}

Several questions remain unanswered by this study, and must therefore be left for future research, such as why do 
some APRNs have more knowledge of BPDs than others, when most stated they had insufficient experience or education? Another question that arose was-would primary care providers, including APRNs, screen for BPD if the US Preventive Services Task Force recommended it? Another area for future research is the hypothesis that primary care APRNs can increase the detection of BPDs and refer these patients to psychiatric care or PMH-NPs and thus reduce the cost burden of undiagnosed or misdiagnosed BPDs, in addition to decreasing the high rates of suicides in BPDs. Considering the high prevalence and global burden of BPDs, further research needs to explore the knowledge and screening behaviors of nurses and APRNs globally. Efforts need to be focused on nursing and APRN education on BPDs and mental health issues globally as this is a worldwide public health need.

\section{CONFLICT OF INTEREST}

The author confirms that this article content has no conflict of interest.

\section{ACKNOWLEDGEMENTS}

The author warmly acknowledges H. Michael Dreher, $\mathrm{PhD}, \mathrm{RN}$, for overall assistance with the development of the study design, and Thomas L. Hardie, Ed.D, RN, PMHCNS-BC for assistance with the quantitative study design and statistical analysis.

\section{REFERENCES}

[1] Keck PE Jr, Kessler RC, Ross R. Clinical and economic effects of unrecognized or inadequately treated bipolar disorder. J Psychiatr Pract 2008; 14(2)(Suppl. 2): 31-8.

[http://dx.doi.org/10.1097/01.pra.0000320124.91799.2a] [PMID: 18677197]

[2] Hogan MF, Sederer LI, Smith TE, Nossel IR. Making room for mental health in the medical home. Prev Chronic Dis 2010; 7(6): A132. [PMID: 20950539]

[3] Merikangas KR, Akiskal HS, Angst J, et al. Lifetime and 12-month prevalence of bipolar spectrum disorder in the National Comorbidity Survey replication. Arch Gen Psychiatry 2007; 64(5): 543-52. [http://dx.doi.org/10.1001/archpsyc.64.5.543] [PMID: 17485606]

[4] American Psychiatric Association Diagnostic and Statistical Manual of Mental Disorders-V: Am Psychiatr Assoc 2013.

[5] Smith DJ, Griffiths E, Kelly M, Hood K, Craddock N, Simpson SA. Unrecognised bipolar disorder in primary care patients with depression. Br J Psychiatry 2011; 199(1): 49-56.

[http://dx.doi.org/10.1192/bjp.bp.110.083840] [PMID: 21292927]

[6] Gore FM, Bloem PJ, Patton GC, et al. Global burden of disease in young people aged 10-24 years: a systematic analysis. Lancet 2011; 377(9783): 2093-102. [http://dx.doi.org/10.1016/S0140-6736(11)60512-6] [PMID: 21652063]

[7] World Health Organization Global Burden of Disease 2012. Available from: http://www.who.int/healthinfo/global_burden_dis ease/gbd/en/ Global Burden of Disease 2012.

[8] Laursen TM. Life expectancy among persons with schizophrenia or bipolar affective disorder. Schizophr Res 2011; 131(1-3): 101-4. [http://dx.doi.org/10.1016/j.schres.2011.06.008] [PMID: 21741216]

[9] Latalova K, Kamaradova D, Prasko J. Suicide in bipolar disorder: a review. Psychiatr Danub 2014; 26(2): $108-14$. [PMID: 24909246]

[10] Courtet P, Samalin L, Olié E. Antidepressants in bipolar disorder. Encephale 2011; 37(Suppl. 3): S196-202. [http://dx.doi.org/10.1016/S0013-7006(11)70053-7] [PMID: 22212875]

[11] Marangell LB, Bauer MS, Dennehy EB, et al. Prospective predictors of suicide and suicide attempts in 1,556 patients with bipolar disorders followed for up to 2 years. Bipolar Disord 2006; 8(5 Pt 2): 566-75. [http://dx.doi.org/10.1111/j.1399-5618.2006.00369.x] [PMID: 17042830]

[12] Akiskal H. Targeting suicide prevention to modifiable risk factors: has bipolar II been overlooked? Acta Psychiatr Scand 2007; 116(6): $395-402$.

[http://dx.doi.org/10.1111/j.1600-0447.2007.01115.x] [PMID: 17997720]

[13] Drancourt N, Etain B, Lajnef M, et al. Duration of untreated bipolar disorder: missed opportunities on the long road to optimal treatment. Acta Psychiatr Scand 2013; 127(2): 136-44.

[http://dx.doi.org/10.1111/j.1600-0447.2012.01917.x] [PMID: 22901015]

[14] Baldassano CF. Assessment tools for screening and monitoring bipolar disorder. Bipolar Disord 2005; 7(Suppl. 1): 8-15. [http://dx.doi.org/10.1111/j.1399-5618.2005.00189.x] [PMID: 15762864]

[15] Ramsley SE. Unipolar or bipolar depression? Improving diagnostic confidence with the adult patient. J Am Acad Nurse Pract 2007; 19(4): $172-8$.

[http://dx.doi.org/10.1111/j.1745-7599.2007.00214.x] [PMID: 17430538] 
[16] Tugrul K. The nurse's role in the assessment and treatment of bipolar disorder. J Am Psychiatr Nurses Assoc 2003; 9(6): 180-6. [http://dx.doi.org/10.1016/j.japna.2003.10.005]

[17] Shalala D. The future of nursing: Leading change advancing health. In: Washington, DC: National Academy of Sciences. 2010. Available from: http://www.iom.edu/nursing. [cited January 4, 2012].

[18] Leech NL, Onwuegbuzie AJ. A typology of mixed methods research designs. Qual Quant 2009; 43(2): 265-75. [http://dx.doi.org/10.1007/s11135-007-9105-3]

[19] Creswell J, Ed. Research design: Quantitative and qualitative approaches. Thousand Oaks, CA: Sage 2003.

[20] Creswell J. Qualitative inquiry and research design: Choosing among five approaches. SAGE Publications 2012.

[21] Lincoln YS, Guba EG. Naturalist inquiry. Beverly Hills, CA: Sage 1985.

[22] Loganathan M, Lohano K, Roberts RJ, Gao Y, El-Mallakh RS. When to suspect bipolar disorder. J Fam Pract 2010; 59(12): 682-8. [PMID: 21135922]

[23] El-Mallakh R. When to suspect bipolar disorder. J Fam Pract 2010; 59(12): 682-8.

[24] Mental health: a report of the Surgeon General-executive summary. Rockville, MD: US Department of Health and Human Services. Substance Abuse and Mental Health Services Administration, Center for Mental Health Services, National Institutes of Health 1999 ; p. 8.

[25] Amiel JM, Pincus HA. The medical home model: new opportunities for psychiatric services in the United States. Curr Opin Psychiatry 2011; 24(6): 562-8. [PMID: 21918447]

[26] Phillips RL Jr, Miller BF, Petterson SM, Teevan B. Better integration of mental health care improves depression screening and treatment in primary care. Am Fam Physician 2011; 84(9): 980. [PMID: 22046936]

[27] Reitz R, Fifield P, Whistler P. Integrating a behavioral health specialist into your practice. Fam Pract Manag 2011; 18(1): 18-21. [PMID: 21302881]

[28] World Health Organization and World Organization of Family Doctors (Wonca). Integrating Mental Health Into Primary Care: A Global Perspective 2008 .

[29] Scott RE. 6 Global e-health policy: From concept to strategy. Royal Society of Medicine Press Ltd 2009.

[30] Depp CA, Stricker JL, Zagorsky D, et al. Disability and self-management practices of people with bipolar disorder: a web-based survey. Community Ment Health J 2009; 45(3): 179-87. [http://dx.doi.org/10.1007/s10597-008-9174-3] [PMID: 19067162]

[31] Todd NJ, Jones SH, Lobban FA. What do service users with bipolar disorder want from a web-based self-management intervention? A qualitative focus group study. Clin Psychol Psychother 2013; 20(6): 531-43. [http://dx.doi.org/10.1002/cpp.1804] [PMID: 22715161]

[32] Horgan A, Sweeney J. Young students' use of the Internet for mental health information and support. J Psychiatr Ment Health Nurs 2010; 17(2): 117-23.

[http://dx.doi.org/10.1111/j.1365-2850.2009.01497.x] [PMID: 20465756]

[33] Powell J, Clarke A. Internet information-seeking in mental health: population survey. Br J Psychiatry 2006; $189(3): 273-7$. [http://dx.doi.org/10.1192/bjp.bp.105.017319] [PMID: 16946364]

[34] Leitan ND, Michalak EE, Berk L, Berk M, Murray G. Optimizing delivery of recovery-oriented online self-management strategies for bipolar disorder: a review. Bipolar Disord 2015; 17(2): 115-27. [http://dx.doi.org/10.1111/bdi.12258] [PMID: 25238632]

[35] Sucala M, Schnur JB, Constantino MJ, Miller SJ, Brackman EH, Montgomery GH. The therapeutic relationship in e-therapy for mental health: a systematic review. J Med Internet Res 2012; 14(4): e110. [http://dx.doi.org/10.2196/jmir.2084] [PMID: 22858538]

[36] Hirschfeld RM, Cass AR, Holt DC, Carlson CA. Screening for bipolar disorder in patients treated for depression in a family medicine clinic. J Am Board Fam Pract 2005; 18(4): 233-9.

[http://dx.doi.org/10.3122/jabfm.18.4.233] [PMID: 15994469]

[37] Nimalasuriya K, Compton MT, Guillory VJ. Screening adults for depression in primary care: A position statement of the American College of Preventive Medicine. J Fam Pract 2009; 58(10): 535-8. [PMID: 19874732]

[38] Smith DJ, Forty L, Barnes E, et al. Screening for bipolar disorder: comparing the performance of the Hypomania Checklist (HCL-32) and the Bipolar Spectrum Diagnostic Scale (BSDS) in a UK sample: P188. Bipolar Disord 2009; 1: 81-2. [Abstract].

[39] Garcia P, Freund N, De Diego B, Harkous C, Suarez JA. Misdiagnosis of bipolar disorder. Bipolar Disord 2012; 14 : 75.

[40] Youngstrom EA, Youngstrom JK, Phelps J, et al. An inexpensive screen for family history of mood disorder improves identification of pediatric bipolar disorder. Bipolar Disord 2009; 1: 91.

[41] Goodwin FK, Jamison KR. Manic-depressive illness: Bipolar disorders and recurrent depression. $2^{\text {nd }}$ ed. New York, NY: Oxford University 
Press 2007.

[42] Kilbourne AM, Goodrich DE, O’Donnell AN, Miller CJ. Integrating bipolar disorder management in primary care. Curr Psychiatry Rep 2012; 14(6): 687-95.

[http://dx.doi.org/10.1007/s11920-012-0325-4] [PMID: 23001382]

[43] Gill JM, Chen YX, Grimes A, Klinkman MS. Using electronic health record-based tools to screen for bipolar disorder in primary care patients with depression. J Am Board Fam Med 2012; 25(3): 283-90.

[http://dx.doi.org/10.3122/jabfm.2012.03.110217] [PMID: 22570391]

[44] Gardner HH, Kleinman NL, Brook RA, Rajagopalan K, Brizee TJ, Smeeding JE. The economic impact of bipolar disorder in an employed population from an employer perspective. J Clin Psychiatry 2006; 67(8): 1209-18. [http://dx.doi.org/10.4088/JCP.v67n0806] [PMID: 16965198]

[45] Laxman KE, Lovibond KS, Hassan MK. Impact of bipolar disorder in employed populations. AMJ Manage Care 2008; 14(11): 757-64.

[46] Keks NA, Hill C, Sundram S, et al. Evaluation of treatment in 35 cases of bipolar suicide. Aust N Z J Psychiatry 2009; 43(6): 503-8. [http://dx.doi.org/10.1080/00048670902873680] [PMID: 19440881]

[47] Novick DM, Swartz HA, Frank E. Suicide attempts in bipolar I and bipolar II disorder: a review and meta-analysis of the evidence. Bipolar Disord 2010; 12(1): 1-9.

[http://dx.doi.org/10.1111/j.1399-5618.2009.00786.x] [PMID: 20148862]

[48] Valtonen HM, Suominen K, Mantere O, Leppämäki S, Arvilommi P, Isometsä E. Suicidal behaviour during different phases of bipolar disorder. J Affect Disord 2007; 97(1-3): 101-7. [http://dx.doi.org/10.1016/j.jad.2006.05.033] [PMID: 16837060]

[49] Goossens PJ, Beentjes TA, de Leeuw JA, Knoppert-van der Klein EA, van Achterberg T. The nursing of outpatients with a bipolar disorder: what nurses actually do. Arch Psychiatr Nurs 2008; 22(1): 3-11. [http://dx.doi.org/10.1016/j.apnu.2007.05.004] [PMID: 18207051]

[50] Jónsdóttir H, Engh JA, Friis S, et al. Measurement of insight in patients with bipolar disorder: are self-rated scales developed for patients with schizophrenia applicable? J Nerv Ment Dis 2008; 196(4): 333-5. [Report]. [http://dx.doi.org/10.1097/NMD.0b013e31816a62b2] [PMID: 18414129]

[51] Jönsson PD, Wijk H, Skärsäter I, Danielson E. Persons living with bipolar disorder-their view of the illness and the future. Issues Ment Health Nurs 2008; 29(11): 1217-36. [http://dx.doi.org/10.1080/01612840802370764] [PMID: 18979326]

[52] Sajatovic M, Ignacio RV, West JA, et al. Predictors of nonadherence among individuals with bipolar disorder receiving treatment in a community mental health clinic. Compr Psychiatry 2009; 50(2): 100-7. [http://dx.doi.org/10.1016/j.comppsych.2008.06.008] [PMID: 19216885]

[53] Frances A, Jones KD. Bipolar disorder type II revisited. Bipolar Disord 2012; 14(5): 474-7. [http://dx.doi.org/10.1111/j.1399-5618.2012.01038.x] [PMID: 22834459]

(C) Ann Marie Kriebel-Gasparro; Licensee Bentham Open.

This is an open access article licensed under the terms of the Creative Commons Attribution-Non-Commercial 4.0 International Public License (CC BY-NC 4.0) (https://creativecommons.org/licenses/by-nc/4.0/legalcode), which permits unrestricted, non-commercial use, distribution and reproduction in any medium, provided the work is properly cited. 